\title{
Slips, lapses and mistakes in the use of equipment by nurses in an intensive care unit
}

\author{
Deslizes, lapsos e enganos no uso de equipamentos por \\ enfermeiros na unidade de terapia intensiva \\ Deslices, lapsos y engaños en el uso de equipos por \\ enfermeros en la unidad de cuidados intensivos
}

Gabriella da Silva Rangel Ribeiro ${ }^{1}$, Rafael Celestino da Silva², Márcia de Assunção Ferreira², Grazielle Rezende da Silva ${ }^{1}$

How to cite this article:

Ribeiro GSR, Silva RC, Ferreira MA, Silva GR. Slips, lapses and mistakes in the use of equipment by nurses in an intensive care unit. Rev Esc Enferm USP. 2016;50(3):419-426. DOI: http://dx.doi.org/10.1590/S0080-623420160000400007

${ }^{1}$ Universidade Federal do Rio de Janeiro, Escola de Enfermagem Anna Nery, Núcleo de Pesquisa de Fundamentos do Cuidado de Enfermagem, Rio de Janeiro, RJ, Brazil.

2 Universidade Federal do Rio de

Janeiro, Escola de Enfermagem Anna

Nery, Departamento de Enfermagem

Fundamental, Rio de Janeiro, RJ, Brazil.

\begin{abstract}
Objective: To identify the occurrence of errors in the use of equipment by nurses working in intensive care and analyzing them in the framework of James Reason's theory of human error. Method: Qualitative field study in the intensive care unit of a federal hospital in the city of Rio de Janeiro. Observation and interviews were conducted with eight nurses, from March to December 2014. Content analysis was used for the interviews, as well as the description of the scenes observed. Results: Lapses of memory and attention were identified in the handling of infusion pumps, as well as planning failures during the programming of monitors. Conclusion: Errors cause adverse events that compromise patient safety. The authors propose creation of an instrument for daily checking of equipment, with checks throughout the work process in the programming of infusion pumps and monitors, in order to reduce failures and memory lapses.
\end{abstract}

\section{DESCRIPTORS}

Critical Care Nursing; Patient Safety; Intensive Care Units; Biomedical Technology. 


\section{INTRODUCTION}

The National Patient Safety Program (NPSP) has the general objective to contribute to the quality of care in all health facilities in Brazil, in partnership with the national public Unified Health System (SUS). For its effective deployment, one strategy of the NPSP is implementation of various methods to provide professionals and students with education, orientation and training on patient safety ${ }^{(1)}$.

One of the areas of interest of the program is safe use of equipment, given the variety of devices, manufacturers, technical specifications to operate each equipment, and the need for knowledge and attention to manage these aspects ${ }^{(1)}$.

This concern is based on evidence from the literature on the occurrence of user errors in the handling of equipment, especially in the intensive care unit (ICU) environment ${ }^{(2-5)}$, which has a large presence of such equipment. Equipmentrelated incidents, known as adverse events ${ }^{(1)}$, have caused harm to patients, as shown in studies on this subject. For example, one study in France compared records from 1998 with those from 2005-2006 to determine whether the number, severity and causes of adverse events related to equipment used in ICUs in the country had changed ${ }^{(2)}$.

The authors concluded that over a period of two years, 76 patients died due to equipment-related incidents, and 197 were victims of severe incidents. Human error was the cause of one-third of incidents in general, and the main cause of those which were classified as severe, showing that the number of incidents resulting from the improper use of equipment increased between the two periods studied ${ }^{(2)}$.

Incorrect use was also identified in another study that tracked and categorized incidents with equipment. In that study, 358 of 1,021 adverse events analyzed were due to incorrect use of equipment, making it the most frequent cause of harm to patients. The authors noted that of the 1,021 adverse events studied, 29 were associated with more than temporary damage, which resulted in longer stay in the ICU, permanent damage and interventions to maintain life and even possible reasons for death ${ }^{(3)}$.

Findings from a third study that measured the stimulusresponse time of the health team to alarms from monitoring equipment in intensive care corroborated the foregoing studies. In 40 hours of observation, 227 alarms were triggered, of which 145 were not responded to by the team, in addition to observations of inadequate programming of physiological variables and alarm parameters. This may have implied that alarms were ignored and patient safety was compromised ${ }^{(4)}$.

The present study identified human error as a cause of adverse events, and one of the risk factors involved in incorporating equipment as part of the care provided in the ICU, and hence a factor that requires attention when designing initiatives for patient safety.

In order to deal with this phenomenon, these initiatives require an understanding of human error. From this perspective, the theory of human error, proposed in 1990 by James Reason is useful. Reason's theory is based on cognitive psychology, and seeks to understand the processes that cause human error in an attempt to apply this knowledge in practice by creating mechanisms to counter the harmful effects of such error ${ }^{(6)}$.

Reason defines error "as a general term covering all those occasions in which a traced sequence of mental or physical activities fails to achieve the expected result, and when these failures cannot be attributed to the intervention of chance"(6). Error only occurs in intentional actions, which may be: performance errors, which are slips and lapses; and errors of planning/knowledge, which are mistakes ${ }^{(7-8)}$. Slips are observable actions that occur differently from the prescribed plan, and lapses are associated with memory. Mistakes are errors in the selection of a goal or the means to achieve $\mathrm{it}^{(7)}$.

Based on the evidence of user error problems in the use of equipment, there is a need to understand this phenomenon under the lens of these concepts. In the present study, this understanding is based on nursing in the ICU, because there is a technological dimension to nursing practice in this environment $t^{(9)}$. Nurses need to observe and understand the codes emitted by equipment, in order to care for patients without causing damage. Because technologies applied in ICU care transmit signals from the patient's body by means of technological language, to avoid improper use of these technologies, the correct interpretation of this language is necessary.

Most studies dealing with adverse events in the context of nursing care ${ }^{(10-11)}$ identify faulty use of equipment as one of its causes; however, they do not delve into the characteristics of these incidents in a manner that contributes to the understanding of how and why they occur, so that effective interventions can be adopted. To improve the quality of care, the NPSP foresees the creation of a protocol on the application of technologies. Therefore, it is necessary to have data on the occurrence of this type of adverse event in order to encourage research in this field of patient safety ${ }^{(1)}$.

The research question for the present study was: What is the nature of the use of equipment by nurses working in the ICU, and what is the relationship between such use andthe occurrence of errors? This study aimed to identify the occurrence of errors during the use of equipment by nurses working in intensive care, and to analyze them from the lens of James Reason's theory of human error.

\section{METHOD}

This was a descriptive and qualitative field study that applied Reason's theory of human error ${ }^{(6-8)}$. Selection of this analytical framework was justified by the fact that it was adopted by the NPSP to discuss unsafe acts in care practice, and propose measures that maximize patient safety.

The field of study was the ICU of a federal university hospital located in the municipality of Rio de Janeiro. Data were produced from March to December 2014. The authors decided to conduct research during the day shift, since the most direct care interventions for the patient that require the use of technological devices occur during this shift. The high incidence of care, which include diagnostic and therapeutic procedures during this shift justifies such a choice, as it provides more opportunities to observe the ways that nurses deal with technologies. 
Participants were nurses who met the following inclusion criteria: working in the ICU; directly involved in patient care; and present during the period of data collection.

The ICU has an area for clinical patients with nine beds, and an area for surgical patients with six beds. The nursing staff of the clinical unit is composed of two nurses per shift and one nurse for surgery, all of which rotate on a scale of 12 hours of work per 60 hours of rest. The possible number of participants in the day shift were nine nurses, eight of which participated in the study, because one was not present during the data collection period.

The data were produced through systematic observation, which sought to portray the everyday practice of the nurses, and observe how they acted in relation to the use of technologies in patient care in the ICU. To support the interpretation of data, the researcher was embedded in the field, participating in the daily practices of the nursing professionals working in the ICU.

An observation script consisting of two parts was applied, the first part aimed to describe the situation and contained the date and time of observation, information about the patient involved (diagnostic and clinical conditions), and focused on gathering data on the professional training, qualification and performance, in the initial observation by the participant.

The other part of the instrument focused on exploring the object of study. In the interests of the research, it was decided to observe situations centered on the nurses' use of the following equipment: monitoring of hemodynamic parameters, infusion of solutions and nutrients, and ventilation. This choice was based on a previous literature review, which indicated a higher incidence of errors involving these equipment, and which thus guided the construction of this part of the instrument ${ }^{(2-3,5,12)}$.

The information generated was based on configuration of data by the professional; interpretation of the meanings of actions or commands; ability to detect and resolve problems; handling of alarms; handling difficulties; and interruptions, among others. Observation of equipment use was done during the daily care of biological needs, admission and transfer of patients, in the performance of highly complex procedures and techniques, work in times of clinical complications, and the clinical meeting of the nursing team.

The observation data were recorded in a field journal, and detailed description was applied, which is a description of the significant structures from which gestures, rituals, codes and actions are produced, perceived and interpreted by the participants themselves and the researcher ${ }^{(13)}$. Care scenes were then described in detail from notes, which included the account of the subjects who participated ipsis literis; methodological notes of the researcher's impressions; and the narrative of facts by the researcher. At the end, there was a quantitative total of 130 hours of observation.

The researchers then sought to portray the perspective of the participants by interviewing them. The researcher directed questions to the participants involved in the scenes recorded, which were developed from previous analysis of the observed situations. A script with questions that encompassed the following aspects was developed: types of errors, related factors, behavior, and damages to patients. The goal was to support the interpretation by the researcher from analysis of observational data.

Participants were discretely approached at a time after they had performed patient care, and the researcher sought to refer to the situation that they had just experienced. Responses were recorded in the field journal. The interview was used throughout the analysis as support for interpretation of observation data.

Analysis of the scenes recorded was used to translate and explain ${ }^{(13)}$ the procedures adopted by the nurses in their handling of equipment. This enabled the categorization of the errors into two types: lapses and slips in the use of infusion pumps; and, mistakes in the use of monitors, categorizations supported by the guiding theoretical framework of the study ${ }^{(6-8)}$. This was followed up by content analysis of the interviews by a deductive approach, according to the categorization based on their presence in the testimonials ${ }^{(14)}$. These were tracked in the search for the occurrence of content that could portray the meanings provided by the participants to their conduct, particularly those that were indicative of adverse events, providing deeper description of the characteristics of errors, and giving density to the same.

Under this logic, the testimonials were used in counterpoint with the scenes observed. This data supported interpretation through the lens of the theoretical framework, discussing safety in the light of the knowledge gained on the subject.

The project was approved by the Research Ethics Committee at the hospital where the research was undertaken, under Protocol no. 260.345/13, in compliance with Resolution 466/2012 of the National Health Council, on research involving human subjects. Participants signed a free and informed consent form, and their confidentiality was guaranteed by numeric identification by order of observation.

\section{RESULTS}

\section{LAPSES AND SLIPS IN THE USE OF INFUSION PUMPS}

Analysis of the conduct of nurses in their use of machinery during patient care in the ICU revealed a set of situations in which errors were observed that compromised patient safety. Among these errors, those involving infusion pumps (IP) stood out in the reports of the nurses when they conferred meaning to the scenes observed, which indicated the frequency with which the mistakes occur.

The errors occur with the pumps, these are terrible, they are values entered incorrectly, incorrect settings, or when the person forgets that s/he interrupted the infusion for some reason, but forgot to restart it. Only the pumps cause more problems (Nurse 5).

Here, you will find a lot of use errors; don't even talk about the pump (Nurse 2).

The problems with the pumps are the most common, these al ways bappen (Nurse 7). 
The statement above by Nurse 5 indicates that the type of error that occurs with the infusion pumps is in its execution, because the actions of the nurses in their handling of the pumps are not in accordance with the desired intention. One such execution error indicated by this participant is that of lapse. One scene which exemplified this type of error was observed while applying a dressing on a patient by Nurse 2 .

Nurse 2 noticed the alarm emitted by an infusion pump and, after analyzing it, called the nursing technician and said: - Look, this pump is sounding an alarm all the time; you changed the diet and forgot to reset the volume. The technician then responded: - I always forget that! (Excerpt from field journal, Nurse 2, 4/24/2014, 9:00am-12:00pm).

These interruptions can have serious consequences on patients. In the meanwhile, as in the situation described above, when the interruption is not identified, the patient does not receive the proper amount of nutrients, which implies the administration of a volume less than prescribed. In the case of medications, interruptions can have immediate effects on hemodynamic changes and clinical evolution.

These memory lapses in recording parameters show that when devices are programmed, they require special attention by the nurses, especially those in management, and also when this function is delegated to another member of the team. This is particularly important when, in analysis of the field journal, the occurrence of slips was verified when entering values of infusion rates of medicines and nutrients to patients in pumps, as noted in the scenes described below.

In the first one, the slip was identified in a condition of heart failure. During resuscitation attempts, Nurse 8 evaluated the infusions for the patient and noted that the pump that infused the sodium nitroprusside - a vasoactive used in the treatment of severe hypertension - was programmed for $10 \mathrm{ml} / \mathrm{h}$, when the prescription was $1 \mathrm{ml} / \mathrm{h}$. When Nurse 8 questioned who had programmed the infusion pump, one of the nursing technicians responded: - I'm the one who programmed it, but I think I programmed it for $1 \mathrm{ml} / \mathrm{h}$. (Excerpt from field journal, Nurse 8, 10/21/2014, 07:30am-12:30pm).

A slip in programming of the IP was also repeated during an episode of accidental extubation. The emergency physician was contacted to perform new intubation, and in the course of this procedure, asked the nursing technician to administer $1 \mathrm{ml}$ of Fentanyl for sedation. The nursing technician pushed a button on the IP which triggered a flush (rapid infusion), but did not perceive the alarm that signaled the end of the prescribed volume of infusion. As a result, rather than administering $1 \mathrm{ml}, 5 \mathrm{ml}$ of Fentanyl were infused.

Following the event, Nurse 7 questioned the technician about the incident, to which she responded: - I kept pressing the button to do a bolus, but I didn't hear the alarm that indicates $1 \mathrm{ml}$. When I looked, it was already at 5, and then I stopped. I swear I didn't hear it! Nurse 7 continued: - Look, when it is like that, don't rely just on alarms, always look at the monitor to check properly. I know that the screen is small, but we have to be careful not to have a bigger problem (Excerpt from field journal, 10/7/2014, Nurse 7,07:30am-12:30pm).
This data shows the existence of factors related to the user, such as the ability to hear and see, as well as factors related to the machinery, including a small screen, which interferes with the user-machine interface, and must be taken into account in analysis of systemic errors. This assertion is corroborated by the following excerpt of the interview with Nurse 7, when she described other experiences with problems with the IP. She commented:

Once I installed a diet in a patient that was supposed to be $65 \mathrm{ml} / \mathrm{h}$, and I ended up programming it for $655 \mathrm{ml} / \mathrm{h}$. My finger is fat, because I am chubby. So I did not pay attention to the value, and I started the diet. A few minutes later I looked at the bottle and it was half empty. I quickly stopped the diet, and nothing happened to the patient.

She continued: The other day, a nursing technician entered norepinephrine at $11 \mathrm{~m} / / \mathrm{h}$ for a patient who needed $1 \mathrm{ml} / \mathrm{h}$. Soon afterwards, the monitor perceived the increased blood pressure, the infusion was interrupted, and nothing happened to the patient because of it. But these buttons are very small, and the display too, which gets in the way. In my opinion, these could be larger to help us (Nurse 7).

In her statement above, Nurse 7 demonstrated a tendency to minimize the consequences of the errors. However, errors in programming of the IP results in adverse events, some of which require intervention to save the patient's life, as in the event described below.

At 10:30 am the female patient, 72 years old, diagnosed with cirrhosis and pulmonary emphysema, breathing ambient air, presented an episode of vomiting accompanied by a drop of $\mathrm{SaO} 2$ by $85 \%$ and intense breathlessness - symptoms suggestive of pulmonary aspiration. Upon reaching the patient's bed, Nurse 1 and the nursing technician detected the problem and analyzed her condition. The technician stated: It was the diet, it is set to $625 \mathrm{ml} / \mathrm{h}$ (the correct ratio was $62.5 \mathrm{ml} / \mathrm{h}$ ). I made a mistake. Nurse 1 responds: We are going to deal with this now, and we can talk about it later. The physician was called for endotracheal intubation and start of artificial ventilation (Excerpt from field journal, Nurse 1, 12/17/2014, 07:30am-12:30pm).

\section{MistAKES IN THE USE OF MONITORS}

The use of monitoring systems demonstrated the presence of mistakes that put patients at risk. The incorrect parameterization of monitors interferes in the transmission by these machines of the vital signs sent by the patient's body, and that are indicative of clinical changes. Detection of these changes by the multidisciplinary team is impeded, causing delays in adopting therapeutic conduct.

This type of planning failure came to light when the researcher perceived a major elevation in the blood pressure of a patient $(180 \times 100 \mathrm{mmHg})$ on the multi-parameter monitor. However, the monitoring equipment was not emitting any sound or light to signal the health care team of this change. Upon checking the pre-determined clinical parameters for the alarm of the device, it was identified that they were programmed to signal only if the blood pressure was higher than $220 \times 110 \mathrm{mmHg}$, although this was a patient with no history of hypertension and was using Norepinephrine. 
The nursing technician asked what was happening. After explanation by the researcher, the technician provided the following justification: The nurses program this device when the patient is admitted, sometimes it stays that way, and they always pass by the Box and have the habit of looking even without the alarm. She heads to the post and continues: Nurse 5, have a look because the blood pressure is 18 and it (the monitor) is not sounding an alarm. She's taking Norepinephrine (Excerpt from field journal, Nurse 5, 4/29/2014, 12:40pm-4:40pm).

The lack of an alarm from the monitor indicated by this nursing technician occurred again during transfer of the patient for a CT examination. During repositioning of the patient in bed after her return from the examination, Nurse 3 asked the technician who participated in the transfer: Has he had this blood pressure $(170 \times 100 \mathrm{mmHg})$ the entire time or just since be's been back? The technician responded: He was fine the entire time, this just happened now (Excerpt from field journal, Nurse 3, 5/29/2014, 1:00pm-5:00pm).

However, the equipment was programmed to sound an alarm only if the blood pressure was higher than $200 \times 100 \mathrm{mmHg}$, which denotes that the device did not do so from this pressure oscillation during the transfer of this patient, compromising its detection by the nursing technician.

\section{DISCUSSION}

The results of this study warn that the use of infusion pumps is a cause for concern in relation to equipment safety, because many users make errors when using them. Such data is corroborated by other studies that show the characteristics of incidents involving equipment, the example of those that analyzed international databases of incident notifications related to patient safety.

In the case of the French notification agency, of all the events with equipment reported in 2005-2006, infusion pumps accounted for 44\% (1,843). Of these, of the 694 incidents in which it was possible to investigate the cause with certainty, 39\% were related to improper use ${ }^{(2)}$. Among incidents reported between 2006-2007 to the patient safety agency of the United Kingdom, incidents with syringe/infusion pumps were the most frequent, representing 185 of 1,021 adverse events notified. As for the characteristics of these incidents, $32 \%$ (60) occurred due to incorrect use and $28 \%$ (52) caused life-threatening damage ${ }^{(3)}$.

There is also research indicating that infusion pumps are responsible for between 30 and $60 \%$ of all errors in the administration of intravenous medication ${ }^{(5)}$. This statement is supported by another study on discrepancies between prescription medications for infusions and programming of pumps. Of 296 observations of drug infusions and 231 of intravenous fluids, the frequency of discrepancies between the prescriptions and programming of the pump ranged from $24.3 \%$ for medicines compared to $42.4 \%$ for liquids ${ }^{(15)}$.

In the present study, the situations involving nurses 1 and 8 during the programming of infusion pumps portray the magnitude of this problem and its immediate impact on the patient. The occurrence of a situation similar to that experienced by the nurses who participated in the present study was documented by researchers when the total parenteral nutrition infusion was set to $625 \mathrm{ml} / \mathrm{h}$ (contrary to $62,5 \mathrm{ml} / \mathrm{h}$ ). After 1.5 hours, the error was recognized and the infusion terminated. Despite treatment for hyperkalemia and hyperglycemia, the patient $\operatorname{died}^{(5)}$.

These types of errors of action found in the results and corroborated in the literature are part of the model proposed by Reason to explain the mechanisms that cause the errors. In this explanatory model, the lapses and slips in programming of IPs pertain to the skill level, which is related to carrying out routine activities in familiar surroundings. This refers to routine tasks that are performed automatically and do not require the need for much thought ${ }^{(7)}$.

When errors happen at this level, it indicates that there were failures in monitoring, i.e. a wrong control compared to the demand of the task. This can occur through a lack of attention by the individual or distractions in the environment, such as: fatigue, hours of sleep, use of drugs, fear, anxiety and stress, all of which influence the automatic mode of thinking ${ }^{(7)}$. The influence of these factors on patient safety have been subject of other studies.

Regarding the issue of attention, one study researched interruptions of nurses in their practice and how these impacted patient safety. Interruptions are understood as the suspension of one activity to perform another, and may be a type of intrusion, distraction, pause and discrepancy. The researchers realized that the interruptions had an impact on the cognitive process, causing loss of concentration and affecting performance of activities by increasing the risk of errors, especially in the administration of medicine $\mathrm{e}^{(16)}$.

Another study sought to identify the association between the allocation of nursing staff and the occurrence of adverse events and incidents. The mean of the adverse events was greater when the nursing staff was improperly distributed in both sectors of the ICU investigated, leading to the conclusion that the larger the difference between nursing hours available compared to those required by patients, the lower the frequency of adverse events ${ }^{(17)}$.

Shifts and long working hours, in turn, increase the risk of sleep disorders and fatigue-related errors that can have an impact on the patient ${ }^{(18)}$. In another study with 289 nurses, $56 \%$ of the sample showed sleep deprivation and committed more errors in patient care, a characteristic associated with working at night ${ }^{(19)}$.

In the ICU, the handling of drug infusion pumps is a routine activity for professionals, because most hospitalized patients require infusion of these medicines to maintain their hemodynamic stability. After such professionals learn how to handle these devices, they do it automatically, although they recognize the attention that this activity requires.

It is known, however, that care in the ICU is complex and characterized by the simultaneous work of a multidisciplinary team, which gives rise to many events happening simultaneously around the nursing staff. The elements of this environment may contribute to episodes of distraction of the professional in monitoring failures around the use of IPs. In this study, improper control happened in the lapse involving Nurse 2 during the registry of a parameter and as lip occurred 
with Nurse 7, during which the technician that accompanied her did not perceive the alarm sound emitted by the IP.

These slips and lapses identified in the study are indicative of active errors, which are unsafe acts of the people who work directly in the system ${ }^{(7)}$. A systemic approach to these errors, unlike a model that focuses solely on blaming the professional, is based on the premise that human beings are fallible and that these errors are, therefore, expected within the system ${ }^{(7)}$.

This also introduces the concept of latent error, which is an avoidable action within the system, taken on the basis of the decisions of managers. There are latent failures in the system, such as aspects related to the workload, resources available and experience, that in a given moment can activate the condition of latency and result in active errors ${ }^{(7)}$.

One of these latent conditions is addressed by Nurse 7, when she justifies the incorrect programming of the IP, stating that the buttons and the screen on the device were small, making its handling difficult for this professional. In this case, rather than simply classifying this error as active, focusing only on Nurse 7 , analysis of this incident should consider the device design, the environment and the circumstances in which this was used.

One of the perspectives used for the analysis of the adequacy of equipment is called human factors engineering, which evaluates a set of variables that impact the humanmachine interface. Human factors engineering determines whether the design of the device influences its safe and effective use by users in real situations ${ }^{(20)}$.

When the design of the device does not integrate the interaction or interpretation that users make of the device interface, there is the possibility of a user error ${ }^{(5)}$. This relates to the physical design and spacing of buttons; degree of intuitiveness of the design of the device; reverting to default mode without warning; overcrowding of the graphic interface; degree of transparency of operations, and poor feedback to the user about the default mode ${ }^{(5)}$.

With the detailed accounts and investigation of these incidents with the IP and in considering the concepts of human factors engineering, some questions could be asked in this evaluation process based on aspects raised by the user, as visualized in empirical data, namely: are the buttons easy to press; are the buttons properly marked; are the settings visible on the screen of the device. Such an assessment, by helping to understand the reason for the occurrence of this type of error, also helps in improving the design of the equipment, in order to facilitate interface with the user.

Another type of error verified in the results were mistakes. Misunderstandings refer to errors that are associated with the mental processes of judgment when outlining an objective and formulating intentions or selecting the means to achieve them, even if the actions turn out as planned ${ }^{(7)}$. Misunderstandings can be types of mistakes based on rules or knowledge. The mistakes based on rules occur when the rule or procedure is not followed correctly, while those based on knowledge are with regard to not knowing the rule or procedure to be adopted, especially during new situations ${ }^{(7)}$.

In this study, the misunderstanding is evident from the moment one intends to monitor the patient's hemodynamic parameters as part of their therapy. It is necessary to handle the equipment to program the adjoining parameters, from which such devices send alerts to professionals which indicate changes of these parameters. In this case, the program should consider the clinical condition of each client at the time of their admission or during hospitalization.

The data shows, however, registered values inconsistent with the situations presented, with the sending of alerts to nurses 5 and 12 only if the blood pressure surpassed the systolic value of 200. This shows a mistake in selection of the strategy, because the purpose of monitoring with regard to blood pressure changes were achieved, but the blood pressure changes of patients involved in the scenes were not "transmitted" by the machines.

This mistake in the use of equipment results from not following the rule of individualized parameterization of the patient and using random parameters that do not match the clinical reality of the patient. The mistake can also be related to the knowledge required to establish the appropriate reference values, either because of difficulties in interpreting the objective variables about the patient sent by the machine, or in the domain of handling codes of the machine.

One study that highlights a mistake related to a failure to follow the rules of programming of equipment is that which identified the number and characteristics of the alarms of electro medical equipment in a coronary unit. Of a total of 426 alarm signals, 227 were triggered by multi-parameter monitors and 199 by other equipment. All patients observed had electrocardiogram monitoring with heart rate enabled, however, the arrhythmia alarm was activated only in $20 \%$ of patients during the daytime shift and $46 \%$ during the night shift. In addition, monitoring of breathing was turned on in only 9 of the 39 night shift patients ${ }^{(21)}$.

Regarding user training for management of technologies, a literature review was done to survey complications presented by critical care patients during in-hospital transport. In this review, the staff's lack of knowledge was found to be a cause of adverse events, because knowledge-based errors accounted for $54 \%$ of the incidents, including the error of preparation of the equipment ${ }^{(22)}$.

To handle errors, the authors of the study suggest the creation of defensive barriers aimed at intercepting the error and maintenance of the safety of the system ${ }^{(8)}$. Under the view of this lens, a model is proposed that uses the metaphor of Swiss cheese to explain such barriers and the trajectory of an accident. Reason makes an analogy to holes in the cheese to refer to gap sin the defensive barriers on the basis of active and latent errors. When all the gaps are arranged on the same line, the defensive barriers are ruptured, causing the accident ${ }^{(8)}$.

According to this author, certain conditions remain dormant for years until they combine with an active error and generate an accident. To focus on the system, different actions to prevent the error can be performed ${ }^{(8)}$. In Brazil, because concern about safety of equipment is still recent, the strategies aimed at creating defensive barriers are incipient, while French legislation requires anesthesia devices be verified with a standard checklist when opening the operating 
room, and in Germany, there are rules pertaining to the formal training of all users ${ }^{(2)}$.

To deal with the lapses and slip-ups, the literature highlights the importance of evaluating equipment by means of checklists and/or protocols to avoid memory lapses, failures and errors, in addition to standardizing procedures and directing the work $^{(2,23)}$. However, with regard to errors, studies $^{(2-3,5,22)}$ indicate the need for educational improvement among health professionals, particularly nurses. In this perspective, the theoretical, practical and scientific understanding of the technological innovations, incorporating evidence-based practices, promotes clinical competence of nurses, as well as patient safety ${ }^{(24-25)}$.

\section{CONCLUSION}

Errors were identified such as slips, lapses and mistakes in the use of equipment by the nurses in the ICU, mainly in the use infusion pumps and monitoring systems, which involve adverse events that harm patient safety.
Understanding the mechanisms that explain such errors underscores the influence of different aspects, depending on the level at which the activity to be performed is situated. These are, memory and attention lapses in handling of IP ability; planning failures during programming of the monitors; application of rules and knowledge. In the systemic analysis of the errors, the objective is not to identify the culprit for punishment, but to know how the error occurred. This is not to say that there is no responsibility on the part of the nurses, since individual characteristics are also examined, such as relaxed and carefree attitudes.

In the field studied, the authors propose an instrument for daily checking of equipment, where checks are performed of the programming of infusion pumps and monitors, in order to reduce errors and memory lapses. It should be noted that the observation was restricted to the day shift, which limited the number of participants and prevented a larger range of results. In addition, it was not possible to assess the linkages of errors with professional experience.

\section{RESUMO}

Objetivo: Identificar a ocorrência de erros na utilização de equipamentos por enfermeiros que atuam na terapia intensiva, analisandoos à luz da teoria do erro humano de James Reason. Método: Pesquisa de campo, qualitativa, na Unidade de Terapia Intensiva de um hospital federal do Rio de Janeiro. Realizou-se observação e entrevista com oito enfermeiros, de março a dezembro de 2014. Aplicou-se análise de conteúdo nas entrevistas e descrição densa nas cenas observadas. Resultados: Identificaram-se falhas de memória e de atenção no manuseio das bombas infusoras e falhas de planejamento durante a programação dos monitores. Conclusão: Os erros causam eventos adversos que comprometem a segurança do paciente. Propõe-se um instrumento de verificação diária dos equipamentos, com checagens ao longo do processo de trabalho da programação das bombas infusoras e monitores, no intuito de reduzir as falhas e esquecimentos.

\section{DESCRITORES}

Enfermagem de Cuidados Críticos; Segurança do Paciente; Unidades de Terapia Intensiva; Tecnologia Biomédica.

\section{RESUMEN}

Objetivo: Identificar la ocurrencia de errores en la utilización de equipos por enfermeros que actúan en cuidados intensivos, analizándolos a la luz de la teoría del error humano de James Reason. Método: Investigación de campo, cualitativa en la Unidad de Cuidados Intensivos de un hospital federal de Río de Janeiro. Se llevó a cabo la observación y entrevista con ocho enfermeros, de marzo a diciembre de 2014. Se aplicó análisis de contenido en las entrevistas y descripción densa en las escenas observadas. Resultados: Se identificaron fallos de memoria y atención en el manejo de las bombas de infusión y fallos de planificación durante la programación de los monitores. Conclusión: Los errores causan eventos adversos que comprometen la seguridad del paciente. Se propone un instrumento de verificación diaria de los equipos, con chequeos a lo largo del proceso laboral de la programación de las bombas de infusión y monitores, a fin que reducir los fallos y olvidos.

\section{DESCRIPTORES}

Enfermería de Cuidados Críticos; Seguridad del Paciente; Unidades de Cuidados Intensivos; Tecnología Biomédica.

\section{REFERENCES}

1. Brasil. Ministério da Saúde; Agência Nacional de Vigilância Sanitária. Assistência segura: uma reflexão teórica aplicada à prática. Brasília: MS; 2013.

2. Beydon L, Ledenmat PY, Soltner C, Lebreton F, Hardin V, Benhamou D, et al. Adverse events with medical devices in anesthesia and intensive care unit patients recorded in the French safety database in 2005-2006. Anesthesiology. 2010; 112(2):364-72.

3. Thomas AN, Galvin I. Patient safety incidents associated with equipment in critical care: a review of reports to the UK National Patient Safety Agency. Anaesthesia. 2008;63(11):1193-7.

4. Bridi AC, Silva RC, Farias CC, Franco AS, Santos VL. Reaction time of a health care team to monitoring alarms in the intensive care unit: implications for the safety of seriously ill patients. Rev Bras Ter Intensiva. 2014;26(1):28-35.

5. Mattox E. Medical devices and patient safety. Crit Care Nurse. 2012;32(4):60-8.

6. Reason J. Human error. London: Cambridge University Press; 2003.

7. Reason J. Understanding adverse events: human factors. Qual Health Care. 1995;4(2): 80-9.

8. Reason J. Human errors: models and management. BMJ. 2000;320(7237):768-70 
9. Backes MTS, Erdmann AL, Buscher A. The living, dynamic and complex environment care in intensive care unit. Rev Latino Am Enfermagem. 2015;23(03): 411-8.

10. Duarte SCM, Stipp MAC, Silva MM, Oliveira FT. Adverse events and safety in nursing care. Rev Bras Enferm. 2015;68(1):144-54.

11. Duarte SCM, Queiroz ABA, Büscher A, Stipp MAC. Human error in daily intensive nursing care. Rev Latino Am Enfermagem. 2015;23(6):1074-81.

12. Elpern E, Killeen K, Patel G, Senecal PA. The application of intermittent pneumatic compression devices for thromboprophylaxis: an observational study found frequent errors in the application of these mechanical devices in ICUs. Am J Nurs. 2013; 113(4):30-6.

13. Geertz C. A interpretação das culturas. Rio de Janeiro: LTC; 2008.

14. Vaismoradi M, Turunen H, Bondas T. Content analysis and thematic analysis: Implications for conducting a qualitative descriptive study. Nurs Health Sci. 2013; 15(3):398-405.

15. Russel RA, Murkowski K, Scanlon MC. Discrepancies between medication orders and infusion pump programming in a pediatric intensive care unit. Qual Saf Health Care. 2010;19 Suppl 3:S31-5.

16. Monteiro C, Avelar AFM, Pedreira M LG. Interruptions of nurses' activities and patient safety: an integrative literature review. Rev Latino Am Enfermagem. 2015; 23(1):169-79.

17. Gonçalves LA, Andolhe R, Oliveira EM, Barbosa RL, Faro ACM, Daud RM, et al. Nursing allocation and adverse events/incidents in intensive care units. Rev Esc Enferm USP. 2012;46(n.spe):71-7.

18. Johnson AL, Jun L, SongY, Brown KC, Weaver MT, Richards KC. Sleep deprivation and error in nurses who work the night shift. J Nurs Adm. 2014;44(1):17-22.

19. Caruso CC. Negative impacts of shiftwork and long work hours. Rehabil Nurs. 2014; 39(1):16-25.

20. Hyman WA. Human factors: should your medical devices require intensive care? Crit Care Nurs Clin North Am. 2010;22(2):233-41.

21. Bridi AC, Louro TQ, Silva RCL. Clinical Alarms in intensive care: implications of alarm fatigue for the safety of patients. Rev Latino Am Enfermagem. 2014; 22(6):1034-40.

22. Almeida ACG, Neves ALD, Souza CLB, Garcia JH, Lopes JL, Barros ALBL. Intra-hospital transport of critically ill adult patients: complications related to staff, equipment and physiological factors. Acta Paul Enferm. 2012;25(3):471-6.

23. Silva R, Amante LN. Checklist for the intrahospital transport of patients admitted to the intensive care unit. Texto Contexto Enferm. 2015;24(2):539-47.

24. Viana RAPP, Vargas MAO, Carmagnani MIS, Tanaka LH, Luz KR, Schmitt PH. Profile of an intensive care nurse in different regions of Brazil. Texto Contexto Enferm. 2014;23(1):151-9.

25. Oliveira RM, Leitão IMTA, Silva LMS, Figueiredo SV, Sampaio RL, Gondim MM. Strategies for promoting patient safety: from the identification of the risks to the evidence-based practices. Esc Anna Nery. 2014;18(1):122-9. 